\title{
Qualitative Inquiry into Quality of Life among Older Adults in Bhutan
}

\author{
Nidup Dorji*1, Michael P Dunne ${ }^{2}$, Charrlotte Seib ${ }^{3}$ and Sibnath Deb ${ }^{4}$ \\ ${ }^{1}$ Faculty of Nursing and Public Health, Khesar Gyalpo University of Medical Sciences of Bhutan, Bhutan \\ ${ }^{2}$ School of Public Health and Social Work, Queensland University of Technology, Australia \\ ${ }^{3}$ School of Nursing, Griffith University, Australia \\ ${ }^{4}$ Department of Applied Psychology, Pondicherry University, India
}

Received: June 04, 2018; Published: June 19, 2018

*Corresponding author: Nidup Dorji, Faculty of Nursing and Public Health, Khesar Gyalpo University of Medical Sciences of Bhutan, Bhutan

\begin{abstract}
A considerable amount of international research into Quality of Life (QOL) seeks to explain the determinants of health and well-being as we age. Many older adults in Bhutan continue to live traditionally in socially integrated Buddhist communities. Popular understanding of health and QOL to some extent could be different from western populations. This qualitative study employed in-depth interviews with 30 older adults (aged 60 to 83 years). Content analysis generated key themes. Finding indicated most older participants experience good QOL. Close family integration and interpersonal harmony, respect for the older people, spirituality, chronic health conditions and adverse childhood experiences, lack of education, insufficient income, and changes in the sources of practical help in the community influenced QOL. Further research is needed to systematically examine the relative contribution of various factors to health and QOL among elderly people in Bhutan and similar communities.
\end{abstract}

Keywords: Bhutan; Quality of Life; Older Adults; Well-Being

\section{Introduction}

Ageing is affecting all countries of the world [1]. The population of older adults ( $\geq 60$ years) in Bhutan is estimated to increase from $4.7 \%$ in 2005 to $11.2 \%$ in 2045 [2]. Bhutanese communities are largely agrarian with nearly $70 \%$ of the population living in rural areas [3]. However, more and more people are observed to be moving to urban areas in search of better economic futures $[2,4]$, leaving behind older adults in the rural communities to fend for themselves [5,6] and is likely to cause feeling of isolation [7] and self-report poor health conditions [8]. Traditionally, older adults are held in high esteem because of their wisdom and vast experiences in life. However, trend such as urbanization and modernization, likely to change family structures most notably affecting care and support of the older family members [9] as well as cohesion and cooperation of the extended family $[10,11]$. Although some studies in Cambodia and Thailand argue such proponent [12,13], family still remains as the primary source of support for older people in most Asian societies $[9,12]$. Breakdowns in the family values and their support are speculated to lead to a host of psychological illnesses [14]. Empirically, the nuclear family system is increasingly becoming a norm especially in urban areas of Bhutan.
QOL is an elusive concept with various meanings in academic and everyday life [15]. Although, there is no general consensus on a single definition of QOL till date [16], one of the ways to overcome this problem is to have a concept locally defined through their perceived meaningfulness that reflects the individual's lived experiences of the concept [17]. Social relationships and contacts are the most important aspects of QOL [18]. For older adults, relationships with children and grandchildren continue to make up an important component of their QOL [19]. A study among older adults in India revealed better QOL among those living within the joint families [20]. Decline in close family ties is perceived to have negative influence on the health and QOL of older adults [11]. In many parts of the world, disintegration of social connection is felt hard especially among older adults, although it remains to be determined whether this problem is, at this time, is a major feature of Bhutanese society.

Older people's engagement in spiritual activities increases with age [21] since spirituality is believed to enhance QOL [22]. Positive relationships between spirituality, subjective QOL and 
wellbeing have been found in various cultures. For instance, spiritual people are reported to be treated with more respect and experience somewhat higher level of happiness and life satisfaction [23]. Spiritual engagement may be an important associate of QOL among older adults [24], although the mechanism by which spirituality alters health outcomes is debatable. Traditionally, respect for older adults has been built into the social fabric in most Asian countries. However, this may be changing over the time [25] and the extent of changes differs by country [26]. Social norms in Bhutan mandates respect for older adults. However, with rapid socio-economic modernization, change in the family structure and function, education, force of materialism Bhutan continues to face, the seemingly deterioration in respect for older adults and its influence on their QOL remain obvious $[27,28]$.

Every individual experiences stressful events at some point of life [29]. Stressful events such as the adverse childhood experiences (ACEs) greatly influence poor physical and mental health outcomes [30] and QOL of older adults [31]. The experience of childhood adversities and their effects on older adults are currently unknown in Bhutan. Better QOL can be achieved if older adults have fewer diseases, little pain, and able to perform activities of daily living independently [32]. Chronic physical and mental disorders such as depression, anxiety, and cognitive impairment are common in old age [33] negatively influencing QOL [34-36]. With increase in the life expectancy of people in Bhutan, the impact of living with chronic physical and mental disorders becomes an important area of concern to be explored.

Globally, research into determinants of QOL among older adults has a long history with complex findings. However, till date there has been limited research conducted on QOL among older adults in Bhutan. In view of the constant socio-demographic changes and multiple factors associated with QOL of older adults, this qualitative study was undertaken to explore and gain insights into how older adults in Bhutan perceive their QOL, and the factors that may enhance or impair QOL.

\section{Methodology}

\section{Study Design}

This qualitative study was designed with the aim to assess the health conditions, wellbeing, and explore QOL to gain insights into how older adults in Bhutan perceive their QOL. The study was conducted between October 2013 and January 2014.

\section{Sample and Sampling Technique}

A non-probabilistic, purposeful sampling approach enabled access to a diverse group of older adults residing in the capital city of Thimphu. The method of sampling to saturation was applied, whereby recruitment continued concurrently with data analysis, and stopped when the researcher found few new themes emerging after 27 interviews. Therefore, the recruitment was stopped at 30 participants. A total of 18 males and 12 females participated in the in-depth interviews (IDIs). The selection of the participants was not intended to be representative; rather, the purpose was to sample older adults at different venues they come to interact to gain a wide variety of insights. The sample of participants shared similar socio-demographic characteristics. Most of the older participants never received formal schooling due to unavailability of modern education system during their childhood days. However, principal researcher managed to contact few older adults who attended formal schooling.

\section{Data Collection Method}

Interviews were semi-structured and guided by the questions shown in Table 1. Interviews were conducted in Dzongkha, English, Tshanglalo, and Lhotsamkha according to their preference. The principal researcher speaks fluently in all the four languages. No refusals were encountered in this qualitative study. IDIs enabled deep discussion of personal experiences and perceptions on QOL and wellbeing. Prior to the conduct of IDI, potential participants were contacted and offered the opportunity to take part in the study. IDIs were conducted in places convenient to the participants. Time taken for the interviews ranged between 45 to 90 minutes. Participants were asked to approve digital recording of the interview.

Table 1: Guiding questions for the in-depth-interviews.

\begin{tabular}{|c|c|}
\hline 1 & $\begin{array}{c}\text { In general how do most elderly people in Bhutan perceive } \\
\text { their quality of life? }\end{array}$ \\
\hline 2 & $\begin{array}{c}\text { Generally, what do you think are the important things in life } \\
\text { that affects your quality of life? Why do you think those areas } \\
\text { are important? }\end{array}$ \\
\hline 3 & $\begin{array}{c}\text { Do you have some physical and emotional difficulties that } \\
\text { cause problems to your quality of life? Do you have enough } \\
\text { support to help you with these problems? }\end{array}$ \\
\hline 4 & $\begin{array}{c}\text { How important is spirituality in your life? If important, why } \\
\text { do you feel that? }\end{array}$ \\
\hline 5 & $\begin{array}{c}\text { Are you respected as an elderly person by your family, } \\
\text { friends, neighbours and society? Do respects in society affect } \\
\text { yourlity of life? }\end{array}$ \\
\hline 6 & $\begin{array}{c}\text { Thinking about people in your life who are close to you: } \\
\text { Which people do you get most enjoyment from? }\end{array}$ \\
\hline 7 & $\begin{array}{c}\text { Thinking back to your childhood, what stressful or difficult } \\
\text { problems affected your wellbeing then? }\end{array}$ \\
\hline 8 & $\begin{array}{c}\text { Who do most elderly people rely upon for help and support if } \\
\text { they need it? }\end{array}$ \\
\hline
\end{tabular}

All participants were informed that they could withdraw from study at any time without any comment or penalty. Participants were guaranteed that their confidentiality would be maintained, and the findings of the research would be reported anonymously. After the completion of each interview, the record was replayed depending on the wish of the respondent to check whether they agreed with what was said. Many decided not to revisit the recorded interview due to time constraints. After each interview, the record was transcribed. Participants were given a small gift in recognition of their voluntary participation at the end of each interview.

\section{Data Analysis}

Qualitative content analysis is one of the many research approaches employed to analyse textual data. The content analysis method with manual sorting was applied to generate common themes. The content analysis in the current study was designed to 
condense raw data into categories or themes through the process of coding [37]. Inductive reasoning was used in which the themes and categories emerged from the data. As discussed by Hsieh and Shannon [38], content analysis began with counting of words (also called manifest content), and extended the analysis to include the latent meanings and themes [38]. The digital recording of the IDIs contained mixture in all four languages (mostly in Dzongkha and Tsanglalo). Having adequate linguistic competence and knowledge of the people under study, the principal researcher took full responsibility for transcription of the collected data into English. Each transcription was audited for accuracy by revisiting the recorded interviews. Back translation into original was not done due to time constraint and costs involvement which were beyond the control of the researcher. The verbatim notes were de-identified prior to analysis. Themes generated were supported by relevant evocative quotations.

\section{Ethical Consideration}

The Research Ethics Board of Health (REBH/Approval/2011/013 Amendment \#1), Ministry of Health, Thimphu, Bhutan, granted permission to conduct this study.

\section{Results}

Table 2: Demographic information of the study participants $(\mathrm{n}=30)$.

\begin{tabular}{|c|c|c|}
\hline \multicolumn{2}{|c|}{ Socio-Demographic Characteristics } & n (\%) \\
\hline \multicolumn{2}{|c|}{$\begin{array}{l}\text { Age }\{\text { Mean } \pm \text { SD }(\text { min-max): } 73.4 \pm 6.6(60-83)\} \\
\qquad \begin{array}{l}60-69 \text { years } \\
70-79 \text { years } \\
\geq 80 \text { years }\end{array}\end{array}$} & $\begin{array}{c}8(26.7) \\
16(53.3) \\
6(20.0)\end{array}$ \\
\hline \multicolumn{3}{|l|}{ Gender } \\
\hline & Male & $18(60.0)$ \\
\hline & Female & $12(40.0)$ \\
\hline \multicolumn{3}{|c|}{ Marital status } \\
\hline & Married & $12(40.0)$ \\
\hline & Divorce & $3(10.0)$ \\
\hline & Widow & $15(50.0)$ \\
\hline \multicolumn{3}{|l|}{ Religion } \\
\hline & Buddhist & $28(93.3)$ \\
\hline & Hinduism & $2(6.7)$ \\
\hline \multicolumn{3}{|c|}{ Education level } \\
\hline & No formal schooling & $26(86.7)$ \\
\hline & Completed high school & $1(3.3)$ \\
\hline & Completed college & $3(10.0)$ \\
\hline \multicolumn{3}{|c|}{ Region of origin } \\
\hline & East & $17(56.7)$ \\
\hline & West & $9(30.0)$ \\
\hline & South & $2(6.7)$ \\
\hline & Central & $2(6.7)$ \\
\hline \multicolumn{2}{|c|}{ Language spoken } & \\
\hline & *Dzongkha & $10(33.3)$ \\
\hline
\end{tabular}

\begin{tabular}{|c|c|c|}
\hline & †Tshanglalo & $18(60.0)$ \\
\hline & $\ddagger$ Nepali & $2(6.7)$ \\
\hline
\end{tabular}

Note: *Language widely spoken by western people of Bhutan and is also the official language of Bhutan

†Language widely spoken by eastern people of Bhutan

‡Language widely spoken by Nepalese origin residing in different parts of Bhutan

The 30 (male=18, female=12) study participants' ages ranged between $60-83$ years (Mean: 73.4). About $87 \%$ of the participants had no formal education. Half (50\%) of the participants were widowed. The great majority $(93.30 \%)$ of the participants were Buddhist. More than half were from east of Bhutan and therefore Tshanglalo emerged as the main language $(60 \%)$ spoken by most of the participants (Table 2). Interview with each respondent deepened with discussion on how they perceived their QOL. Participants identified both positive and negative dimensions of QOL.

\section{Harmonious Family and Social Relationships}

Most of the older participants credited that their ability to give help and support to their children and family such as having successfully sent their children to school, the children gaining decent jobs and income, and in turn finding themselves being looked after well by their children were the main sources of their QOL. Quite a lot of older adults admitted that not having arguments, nuisance, troubles, and misunderstanding with any people in their family and local community is important for QOL. "All my neighbours are good to me and they are all happy seeing me. They tell me that I am the person who does not create nuisance or misunderstanding with neighbours. They love me and respect me." (Male, 75 years, widowed). Some of the older adults credited their good QOL to their successful marriage. Successful marriage is defined according to them as having long lasting married life with no misunderstanding, and the partners are always there to help each other. "I am totally satisfied with my married life. It is a very fruitful, successful and wellcoordinated one. I have been married for the last 33 years. I have had no misunderstanding with my wife at any level of our life. What's going to happen after this is another issue, but till now we have been living a very happy married life." (Male, 62 years, married).

\section{Filial Piety and Respect}

The majority of the older participants emphasized being respected by their family members including children, grandchildren, great grandchildren, relatives, and friends. "As an elderly person from my village, many of my relatives come to see me, and offer me products of their first harvest. They offer me locally brewed wine, betel quid, which I like and I consider is a kind of respect from them." (Male, 78 years, married). While respecting older adults are customary, some respondents felt that the trend for declining respect makes them feel lonely, disconnected, disappointed, hopeless and depressed. "Compared to earlier days, the trend of respecting older adults has changed. The kind of respect in schools and institutions has definitely changed, and the level of respect for elders has declined. The present generation does not 
appreciate what respect is, particularly in terms of discipline." (Male, 63 years, divorced). "We have come to the stage where children have denied acknowledging their parents if their parents have failed to live up to the standard of the society." (Male, 67 years, married).

\section{Source of Enjoyment and Availability of Practical Help and Support}

The primary source of enjoyment and happiness for most of the older people entailed being with children and grandchildren. These close relatives are also the immediate persons to count on in times of need and support, besides spouse, friends, neighbours, and siblings. "Relying to my children is far better than relying on anyone else in life." (Female, 67 years, widowed). However, there is some apprehension and feeling of insecurity over the kind of support they may get especially living in the modern world. "There are instances where older adults are not cared by their children. I am worried that such things might happen to me. I have also heard children today feel the burden of the presence of their parents and grandparents. The elderly have nothing to contribute to their children. Seeing and hearing such incidences make me worry and gets mentally disturbed." (Female, 66 years, married). An elderly respondent who recently left his village to live with his children said: "I cannot be of any contribution to my children. I worry and feel insecure thinking if my children will continue looking after me and my welfare. As a parent, I have given to them my best love and care. These days, looking after the welfare of one's own parents have become conditional among children. This is depressing." (Male, 70 years, married).

\section{Socioeconomic Status}

Several participants emphasised the basic need for money and property. However, some said that as they grow older, one source of satisfaction is that they were now mostly free from cravings and desire for wealth and property. "There is no doubt that wealth and money are necessities of life. However, I have noticed that the desires of wealth and money decrease with ageing. For me I have no desire and cravings for wealth, since I am getting old and I know that nothing can be taken along with me when I leave this world forever." (Male, 78 years, married). Although many participants mentioned the obvious benefits of wealth, this was not a strong theme throughout the interviews. Many suggested that they were satisfied as long as they had the basic necessities for life. A participant who stays with her son and daughter-in-law said: "Having adequate and regular meals a day, decent clothing to wear and a roof over my head is enough to lead a happy life, which was a difficulty in early parts of my life due to heavy taxation. People today can have whatever produce they harvest from their cultivated land." (Female, 77 years, widowed).

\section{Educational Opportunity}

Several participants discussed at length the importance of education in life without which living in the modern world can be difficult. They feel education helps broaden thinking capacity and help find ways to earn decent living. Most participants had no formal schooling, and the lack of opportunity to be educated was recognised as one of the hardships they shared with people in their age group. They spoke often of how lack of education reduced their ability to create a prosperous life for their family. "Most of the people who do well in life are those who can speak what they are thinking and can read, and write. Of course there is no guarantee that education alone can make an individual a better person, but possessing it is the gateway to finding better jobs." (Male, 60 years, married). "Since I couldn't enrol into school, I had difficult time bringing up my children especially when I was earning meagre salary. I had to work under someone's order since I had no formal education background. Thinking that the same might happen to my children, I worked hard and put all my children into school. I was also blessed with children who were equally hard working. Today I am staying happily with them. They look after my welfare." (Male, 77 years, divorced).

\section{Childhood Adversities}

Meeting the basic necessities of life was the difficulty faced by most participants during their childhood years. Compulsory labour contribution for state initiated projects seriously impacted their livelihood and some suggested they still feel its negative impact in old age. "We had to work hard in the field and the crops we cultivated and harvested had to be paid to the government. We had no opportunity to take what we had harvested. If we had cultivated paddy, we had to pay the rice; if we cultivated wheat, we had to pay the wheat. In fact everything we harvested had to be paid to the government. There was no possibility for the simple peasants to earn a good living. This is not the case any more in today's time." (Female, 77 years, widowed). "I wished I had remained as a very small child forever, so that I didn't have to go contribute labour, which was unrewarding." (Male, 78 years, widowed). While most of the older participants vividly remembered their adversities and their influence, some participants considered adversities in early childhood may have had good effects in their life. "I consider adversities in early life were good in one way, since they taught us how to work hard and learn to overcome hardship." (Male, 75 years, widowed).

\section{Spirituality}

Bhutanese older adults perceive that spirituality plays an important role in their lives. They expressed engaging into activities such as building religious monuments and regular circumambulation, recitation of mantras and meditation, attending religious events and going for pilgrimage, all contributed to their good QOL. Many perceived that religion limits thinking ill of others, and suppresses unhealthy or socially unpopular desires and cravings. Most of the elderly participants have one aspiration in common which is praying for the wellbeing of the people, country, and for all the sentient beings. "Irrespective of whatever forms of religious acts one may engage, ultimately it culminates down to taming of one's own mind. If a person can master over his mind, there is no doubt that the person will lead a happy life." (Man, 62 years, married). "Spiritual activities helps pave road for life after death. It also helps us discover self and become more aware, explore more of our own potentials, discover hell and heaven within self and teaches the law of cause, conditions and effects." (Female, 73 years, 
widowed).

While the benefit of spirituality in daily lives was expressed by most participants, some older participants mentioned that spiritual activities also involve investment of material goods particularly in the form of money, which may adversely affect the wellbeing of the person and family. "I don't go to extremes when it comes to religion or spirituality. Of course I do offer butter lamps and water every morning in my small altar at home. I also understand spirituality plays an important role in our daily lives, but the fact is I don't know much about its influence. Generally, when sick, most people would go to seek help from a traditional healer, who are usually religious or spiritual. These superstitious healers for most of the time would talk about astrological ideas and the need to perform numerous rituals. Attending such rites involves lots of expense. I have seen people spending more than $\mathrm{Nu}$. 20,000 in performing such rite. There is no way to earn money! Sometimes the expenditure is more than what is earned in a month. If the patient recovers after performing rites, it is fine. If not, the patient and the family become more stressed, guilty, and agitated. That is why I said I am not into extremes when it comes to religion and spirituality. I feel it's becoming more of a commercial business." (Male, 60 years, married).

\section{Physical Health Conditions}

Most of the older participants expressed that maintaining good health of self and family are essential to attain happy and satisfiable life. "I am happy for most of the time, because I don't suffer from any of the common health problems such as diabetes or hypertension which many of my friends suffer from. My children are also fine like me as of now. I don't think that I need anything more than this in life." (Female, 67 years, widowed). "There can be no one so dear to care of my own body, mind, and speech, other than myself. No one can replace me. Therefore, I have the sole responsibility to take care and maintain my own health. Good health condition is the basis for a person doing anything worthy in life. I feel health is very important in life." (Male, 82 years, widowed). The common physical health problems cited were related to musculoskeletal, cardiovascular, and sensory disorders.

"I experience pain on both my knees. I think it is normal for the older people. I have not much problem walking up. However, walking down the path is a big problem for me, since I cannot bend my knees. There are high chances for me to fall down. Besides, I suffer from high blood pressure, for which I have been taking medicine for the past one-and-a- half year. But my eye sight and ears are still good." (Male, 78 years, widowed). "I cannot see at all with my left eye. It has gone blind two years ago. Doctors in the national hospital told me I have a problem with the optic nerve, which is difficult to treat and get cured. Now with my right eye I can hardly see at this age." (Male, 78 years, married). "When I suffer from severe headache, I feel that there is some kind of fireworks going on in my head. When this happens, I hear nothing. Instead, I feel heavy, very heavy, which often makes me have low mood. I have been suffering from this for some time." (Female, 80 years, widowed). Although, physical difficulties (especially musculoskeletal and sensory disorders) were commonly reported, sorrow due to loss of significant people including spouse, and worrying about their children were thought to have the strongest influence on emotional state. Older adults accepted having physical difficulties are natural during ageing. Some suggested doing prostrations has both physical and spiritual benefits. "I was suffering from pain on my knees. I did prostrations of 200 times per day and the pain was gone." (Female, 64 years, widowed).

\section{Discussion}

This qualitative study based on personal interviews was aimed to gain in-depth understanding of QOL perceived by older adults in Bhutan and explore issues that enhance or impair their QOL. Recent study on happiness in Bhutan found 43.4\% (nearly 3\% increases from $40.9 \%$ in 2010) of Bhutanese identified being happy [39]. Consistently, in some ways, the picture emerged from this study is of a relatively happy and well-integrated older population. However, the study revealed some significant challenges. Many older adults perceived weakening of social integration and lamented on the (perceived) decline of spirituality as younger people become more materialistic. Findings from the past studies indicated that materialism negatively influence QOL $[40,41]$.

Some older people said they still have negative feelings because of severe adversities in their childhood and they regret the lack of opportunity to be educated. This is because very few schools of any type existed in Bhutan before the 1960s and men had more access to it [42]. There are practical hurdles as well; few people have little financial security which causes considerable anxiety, and some said they have few family members close to them on whom they can rely in times of need. However, in contrast to western perspective [43], the obvious benefits of wealth did not appear as a strong theme in this study and many mentioned being satisfied as long as they could meet the basic necessities for life. A wide range of adverse life experiences were recorded among older adults in the past studies associated with health and QOL [31,44]. Likewise, the experience of adversities in life appears to have negative influence on QOL of older adults in this study. This information is important to assist in reducing avoidable adverse life experiences particularly the ACEs.

Importantly, the in-depth discussions emphasised that most of the older adults did not see themselves as passive recipients of support; rather, many were active and gained considerable life satisfaction and good QOL from continuing to have meaningful roles in the family and community. Consistent with previous studies, the ability to provide help, guidance, and support to children and family and in turn being looked after well by them were the most frequently mentioned aspects of good QOL [16, 45\&46]. The importance of spirituality and its positive impact on QOL has been described in previous researches [24,47]. This study supported the notion that spirituality and religious observance play an important role in the daily lives of older adults [21], and is widely perceived to promote health and QOL [22]. Some older adults articulated the likely causal pathways of the health benefits quiet clearly, saying that religion teaches how to control desire, anger, 
ignorance, pride, and jealousy, which are considered in Buddhist communities in particular as the source of human suffering [48]. They also expressed that engaging into spiritual activities (e.g. doing prostration) is the way of sustaining simplicity, cleanses the body, speech, and mind for whatever ills they may have done in the endless cyclic existence. Engaging in spiritual activities was seen by many in a straightforward way: its acts to accumulate merit and virtues that are considered essential in life.

Consistent with previous studies, physical difficulties related to heart, musculoskeletal, and problems with special senses were frequently reported in the present study [49]. Suffering from chronic diseases significantly affects poor QOL [36]. However, most Bhutanese older adults in this study indicated they accept such ailments are part of their ageing process. Buddhist holistically perceives disease as an expression of disturbed harmony in life, and also believes Karma (law of cause and effect) as an important contributing factor to health and disease. Such believes enables an individual to accept and cope with painful aspects of life such as suffering from illnesses [48]. The acceptance of chronic conditions or life events as a part of normal aging was also observed among Taiwanese older adults [50]. However, the presence of chronic physical and mental disorders and their influence on QOL of older adults deserve further investigation.

Bhutanese older adults stated that they value being respected by their family members (children, grandchildren, and great grandchildren). In this study, respect was demonstrated by speaking to them politely, greeting them, or consulting them for advices in any major life decisions (such as family matters). Such respect and acknowledgement gives them the feeling of being an important part of the decision making. Similar findings were reported in other Asian societies such as in Thailand, Taiwan, Singapore, Philippine, and China [26,51]. Although the norms of respect for older adults are described as something good and valuable, some participants perceived decline in the respect for older adults making them feel lonely, disappointed, alienated, and depressed. Such erosion in the filial piety signifies the need to mitigate the influence of modernization. The possible benefits of veneration for older adults deserve further research as it is not explored in many cultures including Bhutan.

Most participants accepted the inevitability of change in their personal health and living situation. Many older adults perceived serious threats to society from rapid socio-economic growth and development, despite improved living standard in general. Some participants expressed concern that rapid development taking place in the country would negatively impact community vitality, cohesion and cooperation, and decrease the tradition of reverence for older adults. Such transition causes a sense of insecurity among older adults and the changes in social values makes some older people feel bitter and anxious about being left alone to face life in old age. Consistently, perceived deterioration in family relationships, trusts in neighbours, and sense of belonging to communities were reported in the Bhutan happiness survey 2015 [39]. Finally, findings from this study indicated, older adults in Bhutan prioritise the essence of harmonious social and family relationships, good physical and mental health, and sound spirituality on their QOL.

\section{Conclusion and Implications}

The overall findings from our sample of older adults strongly suggest that older people in general experience good quality of life in Bhutan. Despite this positive picture, many older adults appear to have significant concern about the uncertain future for their family and worry about the preservation of culture and social harmony. This study has generated some insight into issues that may be important for QOL and would help to guide a larger quantitative survey to systematically examine the relative contributions of these factors to variation in QOL and health of older adults in Bhutan. Findings also provided guidance to improve methods of data collection, such as the appropriateness of face-to-face interviews for larger quantitative survey, as majority of the older participants in this study had no formal education background.

There are limitations to this study. As is the general case in most of the qualitative research, knowledge produced from this study might not generalize to other people or other settings because of the non-random sampling technique applied. Selection bias may have occurred, since only those older adults who were available at the data collection sites were included. Those older adults who couldn't make up to the data collection sites may have had important information which has not been captured. Most of the participants recruited at various religious settings may have influenced the types of comments made particularly about spirituality and religion. We also couldn't gain access to medical records of the participants and the reports of their chronic conditions are purely subjective. Given the high prevalence of respondents with no formal education background, the report on their medical conditions may have been compromised.

\section{Acknowledgement}

We also would like to extend our thanks to all the eminent participants of this project. We would also like to thank the Institute of Health and Biomedical Innovation (IHBI), QUT, Brisbane, Australia, for their financial support.

\section{References}

1. Beard JR, Officer A, de Carvalho IA, Sadana R, Pot AM, et al. (2015) The World report on ageing and health: a policy framework for healthy ageing. Lancet 387: 2145-2154.

2. Gross National Happiness Commission (2010) Population Perspective Plan Bhutan 2010: Goals and Strategies.

3. National Statistics Bureau (2005) Results of Population \& Housing Census of Bhutan 2005. Thimphu, Bhutan.

4. Gurung DB, Seeland K (2008) Ecotourism in Bhutan - Extending its benefits to rural communities. Annals of Tourism Research 35(2): 489508.

5. Sharma PK, Singh EH, Jadhav UN, Mahapatra A (Eds.) (2013) Ruralurban migration: A micro level analysis of rural Bhutanese population. Conference Proceedings of the 2nd International Conference on Population and Development.

6. He C, Ye J (2014) Lonely sunsets: Impacts of rural-urban migration on the left-behind elderly in rural china. Population, Space and Place 20(4): 
352-369.

7. Connelly R, Maurer-Fazio M (2016) Left behind, at-risk, and vulnerable elders in rural China. China Economic Review 37: 140-153.

8. Ao X, Jiang DW, Zhao Z (2016) The impact of rural-urban migration on the health of the left-behind parents. China Economic Review 37: 126139.

9. Kabir ZN, Szebehely M, Tishelman C (2002) Support in old age in the changing society of Bangladesh. Ageing and Society 22(5): 615-636.

10. Thinley YJ (2002) Globalisation: A View From Bhutan. Regional Centre for Strategic Studies, Colombo.

11. Helman CG (2007) Culture, health and illness ( $5^{\text {th }}$ edn.), Hodder Arnold, London, UK.

12. Knodel J, Saengtienchai C (2007) Rural parents with urban children: Social and economic implications of migration for the rural elderly in Thailand. Popul Space Place 13(3): 193-210.

13. Zimmer Z, Korinek K, Knodel J, Chayovan N (2008) Migrant interactions with elderly parents in rural Cambodia and Thailand. Journal of Marriage and Family 70(3): 585-598.

14. Ingle GK, Nath A (2008) Geriatric health in India: concerns and solutions. Indian journal of community medicine: official publication of Indian Association of Preventive \& Social Medicine 33(4): 214-218.

15. Bond J, Corner L (2004) Quality of life and older people. McGraw-Hill International; London.

16. Farquhar M (1995) Definitions of quality of life: a taxonomy. J Adv Nurs 22(3): 502-508.

17. Rapley M (2003) Quality of life research: A critical introduction. SAGE Publications Ltd, London, UK.

18. Nguyen TH, Le THH, Nguyen TQC, Hill PS, Walton T (2012) Exploring quality of life among the elderly in Hai Duong province, Vietnam: a rural urban dialogue. Global Health Action 5: 1-12.

19. Cheng ST, Chan ACM, Phillips DR (2004) Quality of life in old age: An investigation of well older persons in Hong Kong. Journal of Community Psychology 32(3): 309-326.

20. Kumar SG, Majumdar A, Pavithra G (2014) Quality of Life (QOL) and Its Associated Factors Using WHOQOL-BREF Among Elderly in Urban Puducherry, India. J Clin Diagn Res 8(1): 54-57.

21. Nilsson J, Grafström M, Zaman S, Kabir ZN (2005) Role and function: Aspects of quality of life of older people in rural Bangladesh. Journal of Aging Studies 19(3): 363-374.

22. Wallace M, Oshea E (2007) Perceptions of spirituality and spiritual care among older nursing home residents at the end of life. Holistic nursing practice 21(6): 285-289.

23. Stavrova O, Fetchenhauer D, Schlosser T (2013) Why are religious people happy? The effect of the social norm of religiosity across countries. Soc Sci Res 42(1): 90-105.

24. Park J, Roh S, Yeo Y (2012) Religiosity, social support, and life satisfaction among elderly Korean immigrants. Gerontologist 52(5): 641-649.

25. Mehta K (1997) Respect redefined: Focus group insights from Singapore. The International Journal of Aging and Human Development 44(3): 205219.

26. Ingersoll Dayton B, Saengtienchai C (1999) Respect for the elderly in Asia: stability and change. International journal of aging \& human development 48(2): 113-130.

27. Dong X, Chang ES, Wong E, Simon M (2012) A Qualitative Study of Filial Piety Among Community Dwelling, Chinese, Older Adults: Changing Meaning and Impact on Health and Well-Being. Journal of Intergenerational Relationships 10(2): 131-146.

28. Knodel J, Chayovan N (2009) Intergenerational Relationships and Family
Care and Support for Thai Elderly. Ageing Int 33(1-4): 15-27.

29. Wu G, Feder A, Cohen H, Kim JJ, Calderon S, et al. (2013) Understanding resilience. Front Behav Neurosci 7: 10.

30. Monnat SM, Chandler RF (2015) Long Term Physical Health Consequences of Adverse Childhood Experiences. Sociol Q 56(4): 723752 .

31. Luhmann M, Hofmann W, Eid M, Lucas RE (2012) Subjective Well-Being and Adaptation to Life Events: A Meta-Analysis on Differences between Cognitive and Affective Well-Being. Journal of Personality and Social Psychology 102(3): 592-615.

32. Chen Y, Hicks A, While AE (2013) Quality of life of older people in China: A systematic review. Reviews in Clinical Gerontology 23(1): 88-100.

33. Clement JP, Leger JM (2006) Psychiatric disorders in non demented elderly people. Bulletin de l'Academie nationale de medecine 190(6): 1175-1185.

34. Brett C, Gow A, Corley J, Pattie A, Starr J, et al. (2012) Psychosocial factors and health as determinants of quality of life in community-dwelling older adults. Quality of Life Research 21(3): 505-516.

35. Saracli O, Akca AS, Atasoy N, Onder O, Senormanci O, et al. (2015) The Relationship between Quality of Life and Cognitive Functions, Anxiety and Depression among Hospitalized Elderly Patients. Clin Psychopharmacol Neurosci 13(2): 194-200.

36. Cankovic S, Nikolic EA, Jovanovic VM, Kvrgic S, Harhaji S, et al. (2016) Quality of life of elderly people living in a retirement home. Vojnosanitetski Pregled 73(1): 42-46.

37. Graneheim UH, Lundman B (2004) Qualitative content analysis in nursing research: concepts, procedures and measures to achieve trustworthiness. Nurse Education Today 24(2): 105-112.

38. Hsieh HF, Shannon SE (2005) Three Approaches to Qualitative Content Analysis. Qualitative Health Research 15(9): 1277-1288.

39. Ura K, Alkire S, Zangmo T, Wangdi K (2015) Provisional Findings of 2015 GNH Survey. $1^{\text {st }}$ edn 2015.

40. Roberts JA, Clement A (2007) Materialism and satisfaction with over-all quality of life and eight life domains. Social Indicators Research 82(1): 79-92.

41. Kashdan TB, Breen WL (2007) Materialism and diminished well-being: Experiential avoidance as a mediating mechanism. Journal of Social and Clinical Psychology 26(5): 521-539.

42. Pain A, Pema D (2004) The matrilineal inheritance of land in Bhutan. Contemporary South Asia 13(4): 421-435.

43. McLaughlin SJ, Connell CM, Heeringa SG, Li LW, Roberts JS (2010) Successful aging in the United States: prevalence estimates from a national sample of older adults. J Gerontol B Psychol Sci Soc Sci 65B(2): 216-226.

44. Donoghue HM, Traviss Turner GD, House AO, Lewis H, Gilbody S (2016) Life adversity in depressed and non-depressed older adults: A crosssectional comparison of the brief LTE-Q questionnaire and life events and difficulties interview as part of the CASPER study. J Affect Disord 193: 31-38.

45. Yeung GTY, Fung HH (2007) Social support and life satisfaction among Hong Kong Chinese older adults: family first? Eur J Ageing 4(4): 219227.

46. Blazer D, Hughes DC, George LK (1992) Age and impaired subjective support: predictors of depressive symptoms at one-year follow-up. The Journal of nervous and mental disease 180(3): 172-178.

47. Yoon DP, Lee EK (2007) The impact of religiousness, spirituality, and social support on psychological well-being among older adults in rural areas. J Gerontol Soc Work 48(3-4): 281-298.

48. Ratanakul P (2004) Buddhism, health and disease. Eubios Journal of 
Asian and International Bioethics 15(5): 162-164.

(c) (P) This work is licensed under Creative

Submission Link: https://biomedres.us/submit-manuscript.php
49. Ahmed S, Shirin S, Mohsena M, Parvin N, Sultana N, et al. (2007) Geriatric health problems in a rural community of Bangladesh. Ibrahim Medical

\begin{tabular}{ll} 
BIOMEDICAL & Assets of Publishing with us \\
RESEARCHES & - Global archiving of articles \\
& - Immediate, unrestricted online access \\
& - Rigorous Peer Review Process \\
\hline
\end{tabular}

